\title{
Application of discrete choice experiment to assess farmers' willingness to report swine diseases in the Red River Delta region, Vietnam
}

\author{
Hoa T.T. Pham ${ }^{\mathrm{a}, *}$, Marisa Peyre ${ }^{\mathrm{b}}$, Tuyen Quang Trinh ${ }^{\mathrm{c}}$, Oanh Cong Nguyen ${ }^{\mathrm{d}}$, \\ Ton Dinh $\mathrm{Vu}^{\mathrm{d}}$, Theera Rukkwamsuk ${ }^{\mathrm{e}}$, Nicolas Antoine-Moussiaux ${ }^{\mathrm{f}}$ \\ ${ }^{a}$ French Agricultural Research Center for International Development (CIRAD), Van Phuc Diplomatic Compound, 298 Kim Ma, Ba Dinh, Hanoi, Vietnam \\ ${ }^{\mathrm{b}}$ French Agricultural Research Center for International Development (CIRAD), Animal and Integrated Risk Management Research Unit (AGIRs), 34398 \\ Montpellier, France \\ ${ }^{\mathrm{c}}$ National Institute of Animal Science, Hanoi, Vietnam \\ ${ }^{\mathrm{d}}$ Center for Interdisciplinary Research on Rural Development (CIRRD), Vietnam National University of Agriculture, Hanoi, Vietnam \\ e Kasetsart University, Bangkok, Thailand \\ ${ }^{\mathrm{f}}$ Fundamental and Applied Research for Animals \& Health (FARAH), University of Liège, Belgium
}

\section{A R T I C L E I N F O}

\section{Article history:}

Received 27 September 2016

Accepted 2 January 2017

\section{Keywords:}

Swine diseases

Willingness to report

Surveillance

Control

Discrete choice experiment

Vietnam

\begin{abstract}
A B S T R A C T
A discrete choice experiment (DCE) is carried out to value socio-economic factors influencing the farmer's decision to report swine diseases and to assess the willingness of farmers to report swine diseases. Data were collected between March and July 2015 in two provinces in the Red River Delta, Northern Vietnam, from 196 pig producers by face-to face interview. A conditional logit model is used to measure the relative importance of the socio-economic factors and calculate the expected probability of disease reporting under changes of levels of these factors. Results of the study indicated that the likelihood of compensation and the type of culling implemented (all or only unrecovered pigs) are the two most important factors influencing farmer reporting. Compensation level, movement restriction and delay in compensation payment also have significant impacts on farmer's decision to report animal disease but they are not as important as the above factors. Three different scenarios including changes in six different factors (attributes) are tested to predict probability of animal disease reporting. Under the current situation (uncertainty of being compensated), only $4 \%$ of the farmers would report swine disease outbreak to the official surveillance system if the culling policy involves all pigs in affected farms. This number is increased to $26 \%$ if culling in affected farms is restricted to unrecovered pigs only. Ensuring certainty of compensation increases reporting probability by up to $50 \%$ and $90 \%$ if all or only unrecovered pigs are destroyed, respectively. The results of this study are important for improving the performance and sustainability of swine disease surveillance system in Vietnam.
\end{abstract}

(c) 2017 Elsevier B.V. All rights reserved.

\section{Introduction}

Passive surveillance is a process whereby animal health information is collected regularly from different sources such as disease reporting by livestock owners, field veterinarians, laboratory diagnostic reports, slaughterhouses and livestock market records (Geering et al., 1999). Farmers' reporting of animal disease plays an important role in the national surveillance system due to their ability to detect a wide range of diseases, their extensive

\footnotetext{
* Corresponding author.

E-mail address: thithanhhoapham@ymail.com (H.T.T. Pham).
}

coverage of the animal population, and their frequent contact with animals (Cameron, 2012). The results of a study comparing three data sources of dairy disease surveillance in New Zealand indicated that farmers recorded the highest number of disease events (14.6 per 1000 cow months at risk) compared to veterinary practices (5.2 per 1000 cow months at risk) and diagnostic laboratories (0.6 per 1000 cow months) (McIntyre et al., 2003). However, the willingness of livestock owners to share animal health information with veterinary authorities is influenced by many socio-economic factors. Cameron (2012) proposed that fear of the negative consequences of disease notification, poor relationship with veterinary services, and farmers' apathy toward disease occurrence and control are the main reasons for farmers failing to report(Cameron, 
2012).The results of a socio-psychological study among pig farmers in the Netherlands indicated that uncertainty about the occurrence of a given disease and the threat of a false alarm, which might have a negative impact on the farm and on the relationship between farmers and veterinarians, were important factors influencing farmer reporting (Elbers et al., 2010). Lack of trust in the control/eradication measures of veterinary authorities is also considered as a barrier to farmers' willingness to report (Elbers et al., 2010; Palmer et al., 2009). Hadorn et al. (2008) indicated that the disease awareness of farmers is an important factor influencing the sensitivity of passive surveillance and that in endemic areas, where animal owners are likely to be aware of the disease, the probability of disease reporting and detection seems to be higher than in areas where the disease is unknown or neglected (Hadorn et al., 2008).Understanding these socio-economic factors is critical for improving the effectiveness of passive surveillance systems.

Various interventions have been suggested to improve the performance of passive surveillance systems based on the investigated farmer's attitude and behavior in animal disease reporting (Bronner et al., 2014; Dung et al., 2006; Elbers et al., 2010; Hadorn and Stärk, 2008; Palmer et al., 2009). The most used methods are enhancing public awareness of priority animal diseases and of the importance of early reporting through mass media, the improvement of relationships between farmers and veterinary staff, provision of incentives for reporting, and provision of appropriate compensation for culling animals (Cameron, 2012). Gilbert et al. (2012) suggested a subsidy for carcass collection and telephone consultations for private veterinarians as two solutions to increase the cost-effectiveness of passive surveillance (Gilbert et al., 2012). Possible solutions suggested to improve animal health surveillance in Vietnam include travel allowances for district veterinarians to facilitate field visiting and communication with farmers, commune para-veterinarians and drug vendors, and improving data analysis capacity at local level (i.e. district and provincial offices) (Dung et al., 2006). In the context of endemic diseases, to maintain the interest and motivation of field actors such as farmers and local veterinarians to report animal disease, animal health information needs to be communicated to the partners to show livestock owners and local veterinarians the direct benefits of their participation in the surveillance network (Doherr et al., 2012). An example of reinforcing passive surveillance in South Australia through subsidies to laboratory testing, incentives for private veterinarians in data collection, and the raising of farmers' awareness of the benefits of surveillance activities resulted in significantly increasing sample submission rate (Clift et al., 2006). Most of these studies were based on a qualitative approach to identify the factors influencing the decision-making process. To our knowledge, only a limited number of studies (Limon et al., 2012; Palmer, 2009) have used quantitative approaches to assess the socio-economic factors influencing farmer reporting.

Stated preference methods are a set of different econometric methods to characterize consumer preferences in cases where markets cannot be observed. They have been widely used in marketing (Lagerkvist et al., 2006; Thong and Hung, 2014; Xu and Wang, 2014), transport, and environmental economics (Adamowicz et al., 1994; Boxall et al., 1996; Hanley et al., 1998; Zander and Garnett, 2011), as well as health economics (Howard and Salkeld, 2009; Rao et al., 2013; Sadique et al., 2013). More recently, they have also been applied to animal science and animal health. Among the different types of stated preference methods, discrete choice experiments (DCE) are more particularly applied to investigating consumer preferences for particular qualities (called attributes) of the product or service. As such, they provide quantitative information on strength of preference, the trade-off between the factors affecting this preference, and the probability of take up of a product, service or innovation (WHO, 2012). Regarding animal products, they have been mobilized to quantify the demand for unobservable attributes, such as animal welfare attributes(Lagerkvist et al., 2006; Liljenstolpe, 2005). DCE is also used to identify and evaluate farmers' decisions regarding animal disease reporting (Oparinde and Birol, 2011) and animal disease control measures (Otienno et al., 2011; Zhang et al., 2014).

The objectives of this work are to measure the relative importance of socio-economic factors that influence the farmer's decision to report disease, and to assess the farmer's willingness to report animal diseases. The results of this study highlight the factors that need to be improved and to what extent, in order to improve the probability of animal disease reporting.

\section{Material and methods}

In this study, the DCE is used to explore farmer's choice in regard to animal disease reporting upon outbreak on his/her farm. This approach was chosen as it allows quantitatively assessing the relative importance of factors influencing farmer's behavior or decision making and evaluating the famer's willingness to report in terms of predicted uptake under the changes of these factors (attributes). Farmer's preference for animal disease reporting was elicited by presenting them a number of hypothetical choices that were constructed by varying combinations of attribute levels (i.e. characteristics of disease notification and control procedures). Participants were required to select one of the alternatives in each choice-set according to their preference. The DCE model is based on random utility theory under the assumption that the farmer chooses the alternative that provides the highest benefit (utility) (McFadden, 1974). Statistical analysis of the response data allows to estimate how much each alternative is preferred and which attributes contribute most to the choice. Monetary unit can be included as one attribute in DCE and the combination of cost data provides an assessment of the cost-effectiveness of alternative options (Kjaer, 2005). Percentage of farmer's willingness to report animal diseases is predicted by modeling the probability of choosing an alternative with specified characteristics (attributes) of disease notification and control. Such information is a critical point of this study.

To conduct DCE, a number of distinct stages such as identification of attributes and assignment of attribute levels, design and construction of choice sets to present to participants, development questionnaire, data collection, and data analysis were implemented step-by-step. The links between steps are crucial as results of DCE are highly sensitive to the systematic and well design of the whole experiment (WHO, 2012).

\subsection{Identification of attributes and assignment of levels}

A total of 18 focus group discussions with pig farmers and keyinformant interviews were carried out in two provinces. The topics tackled were swine diseases, disease priority for surveillance and control, as well as factors influencing the farmer's decision to report swine disease. From the results of group discussions and key informant interviews, six attributes were identified and included in the discrete choice experiment as follow: (1) Uncertainty of being compensated in case of animal disease reporting; (2) Compensation levels in case of animal culling (price per $\mathrm{kg}$ of pig body weight); (3) pig culling in case of disease reporting; (4) administrative procedure for disease notification and getting compensation payment; (5) movement control in case of disease notification; (6) delivery time of compensation payment.

Attribute levels were then assigned on the basis of the survey results and from a literature review on veterinary regulations (MARD, 2008, 2007) in Vietnam. The attributes and attribute lev- 
Table 1

Attributes and attribute levels used in choice experiment.

\begin{tabular}{ll}
\hline Attribute & Levels \\
\hline $\begin{array}{l}\text { Probability of being } \\
\text { compensated }\end{array}$ & Uncertain \\
& Certain \\
Compensation level & VND $24000 / \mathrm{kg} \mathrm{LBW}$ \\
& VND 33600/kg LBW \\
& VND 38400/kg LBW \\
Animal culling policy & Unrecovered pigs \\
& All pigs at farm \\
Administrative procedures of & Simple \\
disease reporting and & \\
compensation payment & \\
& \\
Movement control in outbreak & Complicate \\
area & No movement ban \\
Delivery time of compensation & Movement ban \\
payment & 3 months \\
& \\
& 6 months \\
\end{tabular}

(LBW: live body weight).

els used in the choice experiment are described in Table 1. Detail descriptions of attribute levels are presented in AF Table 1. Compensation level is added as a monetary attribute and expressed as a percentage of the market price for the live body weight (LBW) of a fattening pig, which is then converted into a compensation price (i.e. amount of money per kilogram LBW of culling pig) using a fixed market price of VND 48,000 kg LBW. This price was considered as mean values of pig prices between 2010 and 2013 that were collected during focus group discussion and key-informant interviews. Compensation attribute levels were set at $50 \%, 70 \%$, and $80 \%$ of pig market price per $\mathrm{kg}$ LBW.

\subsection{Experiment design}

A fractional factorial design was used with $\mathrm{R}$ software version 2.15.3 (R core team, 2013) (support.CEs package). An unlabeled choice experiment design was created by the mix-and-match method (rotation.design function). A choice set was generated by randomly selecting one alternative from each set of $\mathrm{N}$ alternatives. The selection process was repeated without replacement until all alternatives were assigned to choice sets (Aizaki, 2012). The number of 36 choice sets of two alternatives was suggested from $R$ output. Given the number of attributes and levels, this number helps to ensure that the design is orthogonal and balanced (Kuhfeld, 2010). To limit the burden for respondents, it was divided into three blocks of 12 choice sets.

\subsection{Questionnaires and data collection process}

Questionnaires were created based on the choice sets using the questionnaire function in the support.CEs package in $\mathrm{R}$ (Aizaki, 2012). Each farmer was asked to answer 12 questions equivalent to 12 choice sets in one block. Each choice set consisted of two unlabeled disease-reporting alternatives and one opt-out alternative (non-reporting alternative). Farmers were asked to consider these three alternatives and choose the option that they considered the best for their situation. Including opt-out option which refer as "do not report" or "do not choose any alternative" in choice sets allowed us to limit the bias of the forced choice and explore the reasons behind farmer's decision.

\subsubsection{Study area and sampling frame}

The DEC survey was conducted between March and July 2015 in eight communes of four districts of two Red River Delta provinces by face-to-face interviews in Vietnamese. The selection of provinces, districts and communes was based on pig density, extent of pig production, diversity of pig farming systems, and occurrence of notified swine infectious diseases (e.g. porcine reproductive and respiratory syndrome (PRRS), foot and mouth disease (FMD), and classical swine fever (CSF)). The two provinces are subsequently referred to in this paper as province " $A$ " and province " $B$ " as part of the confidentiality procedure to ensure anonymous use of the data. Stratified random sampling was carried out based on production types (mixed farm, fattening farm) and production systems (small or large farm, based on a threshold of 20 sows and/or 200 fattening pigs). The list of pig farmers in each commune was obtained from commune veterinarians. It was then stratified into the above-mentioned categories. Pig farmers were selected randomly from the categories and invited to participate in the study with the support of the commune veterinarian and the head of the village. Due to the limited number of large farms in the study area, all large farms were subjected to interviews.

Equations to compute sample size for DCE requires an initial estimation of choice proportion (Bliemer and Rose, 2005) or prior estimates of parameter values of attributes under investigation (Bekker-Grob et al., 2015) which are unknown before implementing the study. Therefore, sample size calculation in this research is based on Orme's approach that considers the number of choice sets, the number of attributes, and the highest number of attribute levels (Orme, 2009). Target sample size was 120 pig holdings in each province (30 large farms and 90 smallholders), including both fattening and mixed farms with the ratio (1:5) like that of fattening holdings and mixed holdings in area. According to the WHO guideline on discrete choice experiments in public health research, a minimum sample size of 30 is required for each sub group (stratified group) of the main sample to perform econometric analysis (WHO, 2012).

\subsubsection{Data collection}

The DCE task started by setting out the objectives of the study, the importance of the farmers' contribution, the security of personal information and their oral consent to participate in the study. Then a scenario of disease occurrence on the farm was described to create a context in which the farmers could make their decision (Table 2). Detailed descriptions of choice sets as well as attributes were made to ensure a clear understanding of the choice process. Probing questions were used to explore related information such as the possibility of selling sick/dead pigs, price of sick pigs as well as the farmer's perception of money obtained in the case of reporting or not reporting. The questionnaires were tested with 17 pig holders and were adjusted to adapt to field conditions such as specifying infected pig age groups and the threshold percentage of infected pigs in the farm triggering disease reporting.

General information was also collected during the interview about the respondents, such as age, education, position, and about the pig farms (herd size, production system).

\subsection{Data analysis}

McFaden conditional logit model was used to analysis DCE data in this study as the model describes the characteristics (attribute and attribute levels) of the alternatives among which the farmer choose to report animal disease and requires the smallest sample size compared to other models (Hauber et al., 2016). The systematic utility $\left(\mathrm{V}_{\mathrm{i}}\right)$ bound to a scenario was modeled as a linear function of attribute levels characterizing the scenario. The expression of the 
Table 2

An example of choice set.

Imagine that more than $40 \%$ of your pigs are sick with clinical signs as suspected cases from one of the three notified diseases (PRRS, FMD, and CSF). Your sick pigs did not respond after 3-5 days of treatment and the live weight of fattening pigs ranged from 20 to $50 \mathrm{~kg}$. Choose one of the following options related to disease reporting to report swine disease in your holding to veterinary or local authorities.

\begin{tabular}{|c|c|c|c|}
\hline Choice set 1 & Alternative A & Alternative B & Neither alternative A or B \\
\hline $\begin{array}{l}\text { Probability of being } \\
\text { compensated }\end{array}$ & $100 \%$ (certain) & $50 \%$ (uncertain) & \\
\hline Compensation level & 24,000 & 33,600 & \\
\hline$(\mathrm{VND} / \mathrm{kg}$ of $\mathrm{LBW})$ & (50\% market price) & (70\% market price) & \\
\hline $\begin{array}{l}\text { Animal culled incase of } \\
\text { disease notification }\end{array}$ & Unrecovered pigs & All pigs at farm & I do not want to report swine disease \\
\hline $\begin{array}{l}\text { Disease reporting and } \\
\text { compensation } \\
\text { procedures }\end{array}$ & Simple & Complicate & \\
\hline $\begin{array}{l}\text { Animal movement } \\
\text { control in outbreak } \\
\text { area }\end{array}$ & $\begin{array}{l}\text { Animal movement } \\
\text { ban }\end{array}$ & $\begin{array}{l}\text { No animal movement } \\
\text { ban }\end{array}$ & \\
\hline $\begin{array}{l}\text { Delivery time of } \\
\text { compensation } \\
\text { payment }\end{array}$ & 3 months & 6 months & \\
\hline $\begin{array}{l}\text { Your choice (Please tick } \\
\text { only one box as your } \\
\text { preference) }\end{array}$ & $\square$ & $\square$ & $\square$ \\
\hline
\end{tabular}

utility model is as follows:

$$
\begin{aligned}
& \mathrm{V}_{\mathrm{i}}=\beta_{0}+\beta_{1} * \text { possibility_compensation }+\beta_{2} * \text { compensation } \\
& +\beta_{3} * \text { animal_des }+\beta_{4} * \text { administrative procedure of } \\
& \text { disease reporting and compensation }+\beta_{5} * \text { movement_ban }+\beta \\
& \text { 6*delivery_compensation }+\varepsilon
\end{aligned}
$$

The utility coefficients $\left(\beta_{1}-\beta_{6}\right)$ were calculated using clogit function in the support.CEs package in R (Aizaki, 2012). Qualitative attributes were coded as dummy variables, and the monetary parameter (i.e. compensation levels) as a continuous variable. Parameter estimation was run separately for the total sample and then according to province (A and B) and production system (small vs. large, mixed vs. fattening). The goodness-of-fit of the models is measured using McFaden pseudo-R squared $\left(\mathrm{p}^{2}\right)$ which can be defined by the log likelihoods of the model with and without predictors. Values from 0.2 to 0.4 for $\mathrm{p}^{2}$ indicate the good fit of the model (McFadden, 1977).

The relative importance of the socio-economic factors influencing farmers' reporting was assessed based on results of the utility model (i.e. the statistical significance, sign and value of the utility coefficients of attributes and the willingness to pay for changes in attribute levels) (WHO, 2012).The farmers' willingness to pay $\left(\mathrm{WTP}_{\mathrm{kl}}\right)$ for level $\mathrm{l}$ of an attribute $\mathrm{k}$ was calculated as the ratio between its utility coefficient $\beta_{\mathrm{kl}}$ and the marginal utility coefficient of compensation (utility coefficient of the monetary unit). The effects of changes on surveillance were then modeled as a probability of choosing reporting alternative under three defined scenarios. The probability of choosing the reporting alternative was estimated according to changes of attribute levels compared to baselines. Three baselines were set up, which differed in regard to culled pig categories and compensation levels. The first two baselines referred to the current situation of swine disease surveillance and control in Vietnam (MARD, 2008, 2007): i) culling of all pigs at infected holdings (upon first outbreak in the region), ii) culling of unrecovered pigs only (upon re-occurrence in the area). The third baseline was established as an unrealistic scenario with the compensation level at $50 \%$ of the market value of the pig and destroying dead/unrecovered pigs only. The full descriptions of the three baselines are as follows:
- Baseline 1: uncertainty of being compensated, culling all pigs at farm, movement restriction, complicated administrative procedures, compensation level equal to $70 \%$ market price of pig, and getting compensation payment after 6 months.

- Baseline 2: uncertainty of being compensated, destroying dead/unrecovered pigs, movement restriction, complicated administrative procedures, compensation level equal to $70 \%$ market price of pig, and getting compensation payment after 6 months.

- Baseline 3: uncertainty of being compensated, destroying dead/unrecovered pigs, movement restriction, complicated administrative procedures, compensation level equal to 50\% market price of pig, and getting compensation payment after 6 months.

The probability of choosing alternative i was predicted from the expected utility $V_{i}$ using the formula as follows (Gerard et al., 2008):

$\mathrm{P}_{\mathrm{i}}=1 /\left(1+\mathrm{e}^{-\mathrm{Vi}}\right)$

The expected utility $V_{i}$ of alternative $i$ was calculated as Formula (1) using the path-worth utilities for the different attributes corresponding with different levels.

\section{Results}

\subsection{Characteristics of sample population}

Of the 240 pig holdings contacted for interviewing, 27 people were unavailable or unwilling to attend the interview and 17 people refused to complete the choice sets when the interviewer explained the scenario. Finally, 196 respondents were included in the analysis.

The mean age of the respondents in both provinces was 48.5 years, ranging from 28 to 70 years (Table 3 ). Most respondents were male, accounting for $85 \%$ of respondents in province $A$ and $74 \%$ in province B. Half the respondents had less than 9 years of education, $47 \%$ reported having graduated high school and $2 \%$ stated they had an intermediate or college degree. The majority of respondents (80\%) had experience in pig production, with 10 years or more of pig raising. Mixed pig holdings represented $81 \%$ of sampled farms (keeping sows, growers, and fattening pigs), while19\% kept fattening pigs only. Small pig holdings with 6 sows and 100 fattening pigs on average were dominant in both provinces, ranging from $79 \%$ in Province A to $88 \%$ in Province B. 
Table 3

Characteristics of interviewed pig farmers.

\begin{tabular}{|c|c|c|c|}
\hline Characteristics & Province $A(n=97)$ & Province B $(n=99)$ & Total sample $(n=196)$ \\
\hline \multicolumn{4}{|l|}{ Gender } \\
\hline Male, n (\%) & $82(84.5 \%)$ & $73(73.7 \%)$ & $155(79.1 \%)$ \\
\hline Female, n (\%) & $15(15.5 \%)$ & $26(26.3 \%)$ & $41(20.9 \%)$ \\
\hline Mean of age (min- max) & $48.4(28-61)$ & $48.7(31-70)$ & $48.5(28-70)$ \\
\hline \multicolumn{4}{|l|}{ Education } \\
\hline Less than year $9, \mathrm{n}(\%)$ & $49(50.5 \%)$ & $51(51.5 \%)$ & $100(51.0 \%)$ \\
\hline High school graduation, n (\%) & $47(48.5 \%)$ & $45(45.5 \%)$ & $92(47.0 \%)$ \\
\hline Intermediate/College, $\mathrm{n}(\%)$ & $1(1.0 \%)$ & $3(3.0 \%)$ & $4(2.0 \%)$ \\
\hline Experience in pig raising (10 years or over 10 years), $n(\%)$ & $79(81.4 \%)$ & $77(77.8 \%)$ & $156(79.6 \%)$ \\
\hline \multicolumn{4}{|l|}{ Production type } \\
\hline Mixed farm, n (\%) & $65(67.0 \%)$ & $94(94.9 \%)$ & $159(81.1 \%)$ \\
\hline Fattening farm, $\mathrm{n}(\%)$ & $32(33.0 \%)$ & $5(5.1 \%)$ & $37(18.9 \%)$ \\
\hline \multicolumn{4}{|l|}{ Production size, $\mathrm{n}(\%)$} \\
\hline Large farm ( $\geqq 20$ sows and/or 200 fattening pigs), n (\%) & $20(20.6 \%)$ & $12(12.1 \%)$ & $32(16.3 \%)$ \\
\hline Smallholder (<20 sows and/or 200 fattening pigs), n (\%) & $77(79.4 \%)$ & $87(87.9 \%)$ & $164(83.7 \%)$ \\
\hline
\end{tabular}

\subsection{Factors influencing the farmer's decision to report a disease event}

Utility coefficients, calculated according to the province (Table 4), prove statistically significant influences of all attributes $(p<0.01)$, except for the administrative procedures of disease reporting and compensation payment on farmer's decision to report animal disease. The attributes' utility coefficients $(\beta)$ for "probability of being compensated" and "animal culling policy" are positive (3.33 and 2.21, respectively), indicating that a farmer would be more likely to report animal diseases in case of certainty of receiving compensation, and in case of a culling policy restricted to non-recovering pigs only. The highest values of these attributes' coefficients indicate that they have the greatest impacts on farmer's decision to report animal diseases. Movement restriction has a negative impact on the farmer's decision to report $(\beta=-0.58$, se $=0.09$ ). Compensation delivery times of 6 months and 1 year obtain negative utility coefficients, indicating that delaying compensation payment reduced the probability of farmers' disease reporting. The utility coefficient of compensation level is positive and significant, higher compensations increasing the likelihood of reporting.

\subsection{Willingness to pay (WTP) for changing attribute levels}

The highest WTP of farmers is obtained for restricting the culling policy to non-recovering pigs only and for shortening the compensation delivery time from 1 year to 3 months, with averages of VND $34,100 / \mathrm{kg}$ and VND $12,300 / \mathrm{kg}$, respectively. There is no significant difference in these WTP between provinces (Table 5). The WTP for the absence of movement restrictions (VND 4700-VND 13,700/kg) and the reduction of compensation delivery time from 6 months to 3 months (VND 6500 to VND 8400/kg) are similarly deemed valuable changes by the farmers. Pig producers in province $B$ are willing to give up more money for the absence of movement restriction than those in province A (average WTP of VND 13,700/kg and VND $4700 / \mathrm{kg}$, respectively). However, this difference is not statistically significant due to the overlap of confidence intervals.

\subsection{Probability of animal disease reporting by farmers}

The probability of farmers to report swine diseases under different scenarios of control policy is represented in Fig. 1. Under the current situation (baselines of the first and the second scenarios) (i.e. uncertainty of being compensated, movement restriction, complicated administrative procedures, compensation level equal to $70 \%$ of market price, and getting compensation payment after 6 months), $4 \%$ (95\% CI: $0.9 \%-14.3 \%$ ) of farmers are willing to report swine diseases in case of culling all pigs in affected farms, while $26 \%$ (95\% CI: 6.2\%-65.4\%) of pig holders would report diseases in their farm if only dead/unrecovered pigs in affected farms are destroyed. Making administrative procedures less cumbersome, allowing free movements of uninfected pigs in the area, and increasing the compensation payment to $80 \%$ of market value does not significantly increase the proportion of farmers willing to report (all between 1 and $3 \%$ of reporting probability in scenario 1 and between 6 and $12 \%$ in scenario 2). In contrast, if farmers were certain of being compensated, probability of disease reporting would rise up to $52 \%$ (in case of culling all pigs in affected farms) (95\% CI: $16.8 \%-85.3 \%)$ and to 91\% (95\% CI: 59.7\%-98.5\%) (in case of destroying dead/unrecovered pigs in affected farms).

Scenario 3, which takes lower compensation level (50\% market value) into account compared to scenario 2 , shows an intermediate improvement in reporting according to the different changes in policy as compared to the first and second scenarios (from $16 \%$ to $25 \%$ reporting and a peak value at $84 \%$ (95\% CI: $47.9 \%-96.8 \%)$ ).

\section{Discussion}

The present analysis tackles the question of under-reporting of animal diseases in the case of Vietnamese pig farmers, focusing on the impact of disease management policies on their decision. Two components of farmers' perception of the policies are pointed as crucial to this decision: the confidence in compensation payment and the acceptability of stamping out strategy. Interestingly, the compensation level is shown to have less influence. Therefore, improvements in disease reporting from an increase of compensation level may be outweighed by defaults in these two crucial factors. On the contrary, complying with farmers' preferences on these two aspects results in a potential reporting probability of $80 \%-90 \%$. Similarly to compensation level, movement restriction and delivery time of compensation are minor although significant decision factors. The administrative procedures for disease reporting do not appear as an important factor.

The methodological choice of expressing compensations as a price per $\mathrm{kg}$ pig was aimed at making the choice more realistic and acceptable for farmers. Therefore, attention was paid to the number of pigs in the sampling procedure and separate analyses were performed for smallholders and larger farms, despite the low number of farmers in the latter category (due to the low frequency of this farm type in the study regions). The very close coefficient estimates between the two groups indicate that the choice sets were well understood by interviewees with similar stakes in the decision-making being revealed. Given this similarity in decision- 
Table 4

Utility coefficient estimates for factors influencing the farmers' decision to report.

\begin{tabular}{|c|c|c|c|}
\hline \multirow[t]{2}{*}{ Attribute } & \multicolumn{3}{|l|}{ Coefficient (95\% CI) } \\
\hline & Province $A(n=97)$ & Province B $(n=99)$ & Total sample $(\mathrm{n}=196)$ \\
\hline $\begin{array}{l}\text { Probability of being } \\
\text { compensated }\end{array}$ & $\begin{array}{l}4.70^{* * *} \\
(4.26 ; 5.14)\end{array}$ & $\begin{array}{l}2.56^{* * *} \\
(2.30 ; 2.81)\end{array}$ & $\begin{array}{l}3.33^{* * *} \\
(3.11 ; 3.54)\end{array}$ \\
\hline \multicolumn{4}{|l|}{ Uncertainty vs. Certainty } \\
\hline Culling pigs & $2.94^{* * *}$ & $1.89^{* * *}$ & $2.21^{* * *}$ \\
\hline \multicolumn{4}{|l|}{ Unrecovered pigs } \\
\hline Administrative procedures & 0.001 & 0.13 & 0.10 \\
\hline Complicated vs. Simple & $(0.31 ; 0.31)$ & $(-0.11 ; 0.37)$ & $(-0.09 ; 0.29)$ \\
\hline Movement control & $-0.42^{* * *}$ & $-0.70^{* * *}$ & $-0.58^{* * *}$ \\
\hline No movement ban vs. & $(-0.69 ;-0.15)$ & $(-0.91 ;-0.46)$ & $(-0.75 ;-0.42)$ \\
\hline \multicolumn{4}{|l|}{ Movement ban } \\
\hline Delivery time of compensation & $-0.57^{* * *}$ & $-0.42^{* * *}$ & $-0.44^{* * *}$ \\
\hline payment & $(-0.90 ;-0.24)$ & $(-0.67 ;-0.17)$ & $(-0.64 ;-0.25)$ \\
\hline 6 months & $-0.81^{* * *}$ & $-0.82^{* * *}$ & $-0.80^{* * *}$ \\
\hline 1 year & $(-1.14 ;-0.48)$ & $(-1.07 ;-0.56)$ & $(-1.0 ;-0.6)$ \\
\hline Compensation levels (per $10^{3}$ & $0.09^{* * *}$ & $0.05^{* * *}$ & $0.06^{* * *}$ \\
\hline $\mathrm{VND} / \mathrm{kg})$ & $(0.06 ; 0.11)$ & $(0.03 ; 0.07)$ & $(0.05 ; 0.08)$ \\
\hline Number of respondents & 97 & 99 & 196 \\
\hline Number of observations & 3492 & 3564 & 7056 \\
\hline Log likelihood of the model & -600.82 & -905.28 & -1557.87 \\
\hline $\begin{array}{l}\text { Log likelihood of the model } \\
\text { without predictors }\end{array}$ & -1278.79 & -1305.15 & -2583.94 \\
\hline McFaden's pseudo $\mathrm{R}^{2}$ & 0.53 & 0.31 & 0.40 \\
\hline
\end{tabular}

CI: Confidence Interval.

*** statistically significant $(\mathrm{p}<0.01)$.

Table 5

Farmers' willingness to pay for changes of attribute levels.

\begin{tabular}{|c|c|c|c|}
\hline \multirow[t]{2}{*}{ Attribute } & \multicolumn{3}{|c|}{ WTP for change in attributes $\left(10^{3} \mathrm{VND} / \mathrm{kg}\right.$ of culling pig) Mean $(95 \% \mathrm{CI})$} \\
\hline & Province $A(n=97)$ & Province $B(n=99)$ & Total sample $(n=196)$ \\
\hline $\begin{array}{l}\text { Culling pigs restricted to } \\
\text { unrecovered pigs }\end{array}$ & $\begin{array}{l}33.4 \\
(25.7,46.2)\end{array}$ & $\begin{array}{l}38.0 \\
(27.2,60.8)\end{array}$ & $\begin{array}{l}34.1 \\
(27.7,43.8)\end{array}$ \\
\hline No movement ban & $\begin{array}{l}4.7 \\
(1.7,8.7)\end{array}$ & $\begin{array}{l}13.7 \\
(8.0,24.0)\end{array}$ & $\begin{array}{l}9.0 \\
(6.0,13.0)\end{array}$ \\
\hline $\begin{array}{l}\text { Delivery time of compensation } \\
\text { changed from } 6 \text { months to } 3 \\
\text { months }\end{array}$ & $\begin{array}{l}6.5 \\
(2.5,12.0)\end{array}$ & $\begin{array}{l}8.4 \\
(3.0,17.1)\end{array}$ & $\begin{array}{l}6.8 \\
(3.6,11.1)\end{array}$ \\
\hline $\begin{array}{l}\text { Delivery time of compensation } \\
\text { changed from } 1 \text { year to } 3 \\
\text { months }\end{array}$ & $\begin{array}{l}9.2 \\
(5.3,14.7)\end{array}$ & $\begin{array}{l}16.3 \\
(10.0,27.6)\end{array}$ & $\begin{array}{l}12.3 \\
(8.7,17.1)\end{array}$ \\
\hline
\end{tabular}

CI: Confidence Interval.

making, the analysis of reporting probabilities is presented here for the whole sample.

The WTP highlights the true barrier that animal culling policy poses on surveillance efficacy. Indeed, farmers would be willing to pay $43 \%-80 \%$ market value of pig to be sure that only nonrecovering pigs are destroyed. Classical stamping-out policy would lead farmers to hide diseases, despite compensation levels as high as $80 \%$ market value of pig as well as the certainty of receiving this money. The motives behind these results were obtained through open qualitative interviews after DCE completion. First, notifiable swine diseases such as PRRS and FMD are endemic in Vietnam and therefore farmers perceive a policy of stamping-out as lacking relevance as they are used to managing these diseases like other endemic production diseases. Most farmers believe in a high probability of successful treatment and a better profit to be expected from recovered pigs than from compensation payment. Compensation level at $80 \%$ market value of pig was considered as covering breeding costs and a part of feeding costs. Farmer estimates the success rate of treatments at $50 \%$, hence a $50 \%$ chance of generating profit. Second, the farmers expect a rise in pig prices after disease outbreaks, creating a particular speculative opportunity. Third, the destruction of clinically healthy pigs is considered unacceptable, being perceived as a waste of resources, food, and valuable genetic asset. Indeed, the culling of clinically healthy breeding stock is unacceptable due to the high value of sows with good performance (i.e. annual number of piglets and piglet weight at weaning, maternal behavior). Most farmers believe that PRRS has no effect on the reproductive performance of sows. Therefore they would not accept the culling of asymptomatic sows even after confirmation of infection.

Compensation is considered as a critical element of effective disease control as it encourages farmers' reporting and compliance with the culling of confirmed or suspected cases of infection, thus reducing the risk of disease spreading (World Bank, 2006). Compensation rate should be no less than $50 \%$ of market value for healthy animals and recommended rates range from 75 to $90 \%$ of the reference price (World Bank, 2006). Lower compensation could be applied for dead animals than for diseased or healthy animals to encourage early reporting (World Bank, 2006). In agreement with the veterinary regulations of Vietnam, the same compensation level was proposed in our study for all categories of destroyed pigs (piglets, fatteners, growers, sows, and boar, dead or sick pigs) (MOF, 2008). This lack of acknowledgement of the higher value of breeding stock appears as a major disincentive for disease reporting. In the context of the avian influenza compensation scheme in Indonesia, contingent valuation was used to quantify such a dif- 


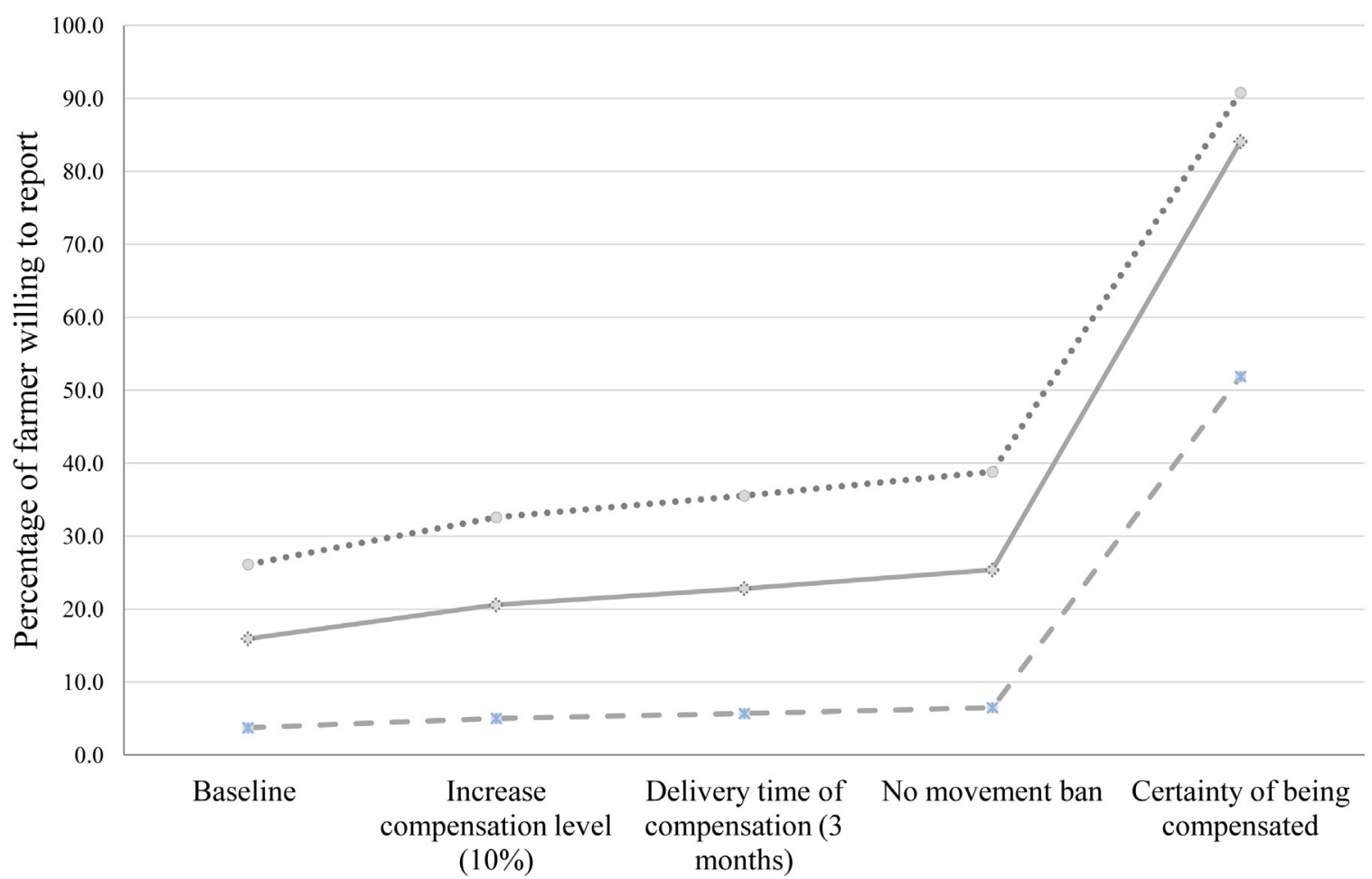

\section{- - Scenario1: Destroying all pigs at farm, compensation of $70 \%$ market value \\ $\cdots$ Scenario2: Destroying dead/unrecovered pigs, compensation of $70 \%$ market value \\ - Scenario3: Destroying dead/unrecovered pigs, compensation of $50 \%$ market value}

Fig. 1. Probability of swine disease reporting by farmers under different scenarios of control policy.

ferentiated willingness to accept compensation for different types of birds (Yakhshilikov et al., 2009). However, our study was not designed to estimate the potential improvement obtained through a differentiated compensation scheme and this question would thus require a specific approach.

The uncertainty and lack of transparency of procedures for culling and compensation payment appear here as barriers for disease reporting. According to Vietnamese disease control policy (MARD, 2008, 2007), culling pigs at farms after confirmation of disease can apply for all pigs in case of a new outbreak or if the outbreak occurs in a limited area (few households in the village/commune) to rule out disease earlier. Culling of solely non-recovering pigs is applied if the outbreak covers a large area or an area where the disease has occurred several times. This flexibility of procedure makes things unclear for farmers. These results suggest the importance of clarifying culling rules with adequate communication strategy.

Findings of the study also emphasize the wider acceptability of restricted culling and the interest to apply this strategy in a maximum of relevant cases. The effectiveness of such targeted culling on PRRS, FMD, and CSF disease control in Vietnam would probably be very limited but similar to the current situation of high level of under-reporting and local disease management strategy. However it would greatly improve the sensitivity of the current surveillance systems provides better epidemiological information on field disease situation and help rebuilding farmers' trust on national surveillance and control policies. On the long run this would provide stronger basis for defining novel control strategies in collaboration with farmers and local stakeholders.
Even though the administrative procedures do not show here a significant influence on farmers' willingness to report $(p>0.05)$, it is expected that simplified and transparent procedures would promote clarity of the system and farmers' trust, which are factors showing a significant effect on reporting. A distrust in veterinary authorities and control measures is, indeed, listed as an important barrier to disease reporting (Bronner et al., 2014; Elbers et al., 2010; Palmer et al., 2009). Here again, the timeliness and reliability of compensation delivery intervene as critical elements in building trust between farmers and officials (World Bank, 2006).

In open interviews following the DCE questionnaire, farmers further justified movement restriction as an obstacle to reporting by the extension of pig keeping time and increase of input cost. These then indicated a willingness to pay for laboratory tests in case of outbreak in their region to maintain the right to free movement. This willingness might also be further explored though contingent valuation and the institutional feasibility of such an arrangement would then need to be assessed. Continuity of business is a particular modality of foot and mouth disease response in the United States, to be applied in combination with quarantine and movement control (USDA, 2015). It allows non-affected farms to sell non-infected animals or non-contaminated animal products out of the control area. This is a solution to maintain agricultural business operations while also mitigate the risk of disease spread. However, it requires not only sampling and testing animals but also assessing farm's bio-security before movement (USDA, 2015).

Few studies have applied DCE in Vietnam in the domain of animal science (Costales et al., 2008; Roessler et al., 2008; Zhang et al., 2014) and its use in animal health surveillance is even more lim- 
ited. DCE provides quantitative evidence of the relative importance of factors influencing individual decision-making, and clarifies the trade-offs between given attributes, thus predicting the probability of uptake in specified alternatives (WHO, 2012). Although DCE is based on hypothetical choice rather than actual choice, the results of studies on the environment (Adamowicz et al., 1994) and public health (Lambooij et al., 2015) have indicated the consistency of stated and revealed preferences. To our knowledge, there is no study comparing the results of stated and revealed preferences on animal health surveillance. The unobservable nature of the choice of not reporting diseases makes it difficult to consider protocols able to make such a comparison. DCE allows for this estimation by the inclusion of an opt-out alternative representing non-reporting behavior in the choice set. Therefore this methodological choice reveals crucial to apply DCE to surveillance evaluation in Vietnam, where underreporting of animal disease is an important feature.

\section{Conclusion}

DCE proved fruitful in the analysis of reporting the behavior of pig farmers in Vietnam. More particularly, it highlights the importance of general or targeted culling strategy. The quantification of expected improvements of reporting probability may be used to model the expected benefits of institutional changes in surveillance policy in Vietnam.

\section{Acknowledgements}

This study was carried out in the framework of the CIRAD- REVASIA project, the CIRAD and IRD joint young researcher team project JEAI-SWEID and with the support of GREASE network. We thank the veterinarians of the sub department of animal health and veterinary stations, and the local authorities in the study area for their support in data collection and all interviewed pig holders for their time and participation in this study.

\section{Appendix A. Supplementary data}

Supplementary data associated with this article can be found, in the online version, at http://dx.doi.org/10.1016/j.prevetmed.2017. 01.002 .

\section{References}

Adamowicz, W., Louviere, J.J., Williams, M., 1994. Combining revealed and stated preference methods for valuing environmental amenities. J. Environ. Econ. Manag. 26, 271-292.

Aizaki, H., 2012. Basic functions for supporting an implementation of choice experiments in R. J. Stat. Softw. 50, 1-24.

Bekker-Grob, E.W., de Donkers, B., Jonker, M.F., Stolk, E.A., 2015. Sample Size Requirements for Discrete-Choice Experiments in Healthcare: a Practical Guide. Patient - Patient-Centered Outcomes Res. 8, 373-384. http://dx.doi.org/ 10.1007/s40271-015-0118-z.

Bliemer, M.C.J., Rose, J.M., 2005. Efficinecy and Sample Size Requirements for Stated Choice Studies. Working Paper ITLS-WP-05-08. Institute of transport and logistics studies. The University of Sydney.

Boxall, P., Adamowicz, W., Swait, J., Williams, M., Louviere, J.J., 1996. A comparision of stated preference methods for environmental valuation. Ecol. Econ. 18, 243-253.

Bronner, A., Hénaux, V., Fortané, N., Hendrikx, P., Calavas, D., 2014. Why do farmers and veterinarians not report all bovine abortions, as requested by the clinical brucellosis surveillance system in France? BMC Vet. Res. 10, 93.

Cameron, A., 2012. Manual of Basic Animal Disease Surveillance. Interafrican Bureau for Animal Resources, Available: www.au-ibar.org/. . ./1546-manual-of-basic-animal-disease (Accessed: August 20, 2015).

Clift, K.H., Weaver, J., Frazer, J.L., 2006. Rebuilding a passive surveillance program. In: Proceedings of the 11 th International Symposium on Veterinary Epidemiology and Economics, Cairns, Australia.

Costales, A., Son, N.T., Lapar, M., Tioncgo, M., 2008. Determinants of participation in contract farming in pig production in Northern Vietnam (Research report No. 8-4). Pro-Poor Livestock Policy Initiative (PPLPI).
Doherr, M.G., Calavas, D., Cameron, A., Dufour, B., Greiner, M., Gustafson, L. Hoinville, L., Knopf, L., Roger, F., Stärk, K.D.C., Salman, M.D., 2012. First international conference on animal health surveillance (ICAHS). Prev. Vet. Med. 105, 165-168, http://dx.doi.org/10.1016/j.prevetmed.2012.03.014.

Dung, D.H., Taylor, N.M., MacLeod, A., 2006. Improving veterinary surveillance in Vietnam- a knowledge management approach. In: The 11th International Symposium on Veterinary Epidemiology and Economics. International Symposia on Veterinary Epidemiology and Economics, Cairns, Australia, Available: www.sciquest.org.nz (Accessed: August 13, 2015).

Elbers, A.R.W., Gorgievski-Duijvesteijn, M.J., van der Velden, P.G., Loeffen, W.L.A., Zarafshani, K., 2010. A socio-psychological investigation into limitations and incentives concerning reporting a clinically suspect situation aimed at improving early detection of classical swine fever outbreaks. Vet. Microbiol. 142, 108-118, http://dx.doi.org/10.1016/j.vetmic.2009.09.051.

Geering, W.A., Roeder, P.L., Obi, T.U., 1999. Manual on the Preparation of National Animal Disease Emergency Preparedness Plans, FAO Animal Health Manual. Food and Agriculture Organization of the United Nations, Rome.

Gerard, K., Shanahan, M., Louviere, J., 2008. Using discrete choice modelling to investigate breast screening participation. In: Using Discrete Choice Experiment to Value Health and Health Care. Springer, pp. 117-137.

Gilbert, W., Hasler, B., Rushton, J., Flood, T., Hoinville, L., Brouwer, A., Tearne, O., 2012. Enhancing passive surveillance: an economic evaluation of alternative methods. In: Proceedings of the 13th International Symposium on Veterinary Epidemiology and Economics. International Symposia on Veterinary Epidemiology and Economics, Belgium, Netherland.

Hadorn, D.C., Stärk, K.D.C., 2008. Evaluation and optimization of surveillance systems for rare and emerging infectious diseases. Vet. Res. 39, 57, http://dx. doi.org/10.1051/vetres:2008033.

Hadorn, D.C., Haracic, S., Stärk, K.D., 2008. Comparative assessment of passive surveillance in disease-free and endemic situation: example of Brucella melitensis surveillance in Switzerland and in Bosnia and Herzegovina. BMC Vet. Res. 4, 52, http://dx.doi.org/10.1186/1746-6148-4-52.

Hanley, N., Wright, R.E., Adamowicz, V., 1998. Using Choice Experiments to value the environment. Environ. Resour. Econ. 11, 413-428.

Hauber, A.B., González, J.M., Groothuis-Oudshoorn, C.G.M., Prior, T., Marshall, D.A., Cunningham, C., IJzerman, M.J., Bridges, J.F.P., 2016. Statistical methods for the analysis of discrete choice experiments: a report of the ISPOR conjoint analysis good research practices task force. Value Health 19, 300-315, http://dx.doi. org/10.1016/j.jval.2016.04.004.

Howard, K., Salkeld, G., 2009. Does attribute framing in discrete choice experiments influence willingness to pay? Results from a discrete choice experiment in screening for colorectal cancer. Value Health 12, 354-363. http://dx.doi.org/10.1111/j.1524-4733.2008.00417.x.

Kjaer, T., 2005. A Review of the Discrete Choice Experiment- with Emphasis on its Application in Health Care, Available: http://static.sdu.dk/mediafiles//Files/ Om_SDU/Centre/c_ist_sundoke/Forskningsdokumenter/publications/ Working\%20papers/20051pdf.pdf (Accessed: August 18, 2015).

Kuhfeld, W.F., 2010. Experimental Design, Efficiency, Coding, and Choice Designs, Available: http://support.sas.com/techsup/tnote/tnote_stat.html\#market (Accessed: December 20, 2014).

Lagerkvist, C.J., Carlsson, F., Viske, D., 2006. Swedish consumer preferences for animal welfare and biotech: a choice experiment. AgBioForum 9, 51-58.

Lambooij, M.S., Harmsen, I.A., Veldwijk, J., Melker, H., de, Mollema, L., Weert, Y.W., van, Wit, de, G.A., 2015. Consistency between stated and revealed preferences: a discrete choice experiment and a behavioural experiment on vaccination behaviour compared. BMC Med. Res. Methodol. 15, 19, http://dx.doi.org/10. 1186/s12874-015-0010-5.

Liljenstolpe, C., 2005. Valuing animal welfare with choice experiments: an application to Swedish pig production. In: Presented at the European Association of Agricultural Economist, Copenhagen, Denmark, August 24-27.

Limon, G., Ruiz, H., Balanza, M.E., Guitian, J., 2012. A mixed method approach investigating factors influencing reporting of animal disease among smallholders in southern Bolivia | SciQuest. In: Proceedings of the 13th International Symposium on Veterinary Epidemiology and Economics, Belgium, Netherland.

MARD, 2007. Ministry of Agriculture and Rural Development. Decision No $5 / 2007 /$ QD-BNN on prevention and control of foot and mouth disease (FMD), dated $22 / 1 / 2007$.

MARD, 2008. Ministry of Agriculture and Rural Development. Decision No $60 / 2008 / Q D-B N N$ on prevention and control of Porcine reproductive and respiratory syndrome (PRRS), dated 15/7/2008.

MOF, 2008. Ministry of Finance. Circulation No 80/2008/TT-BTC on financial support for prevention and control activities in animal health, dated 18/9/2008.

McFadden, D., 1974. Conditional Logit Analysis of Qualitative Choice Behavior, In: Frontiers of Economics. Academic Press, London, pp. 105-142.

McFadden, D., 1977. Quantitative Methods for Analyzing Travel Behaviour of Individual: Some Recent Developments. Cowles Discussion Paper No 474 Cowles foundation research for economics. Yale University.

McIntyre, L.H., Davies, P.R., Perkins, N.R., Morris, R.S., Jackson, R., 2003. A comparison between three sources of endemic animal disease surveillance data. In: Proceedings of the 10th International Symposium on Veterinary Epidemiology and Economics. International Symposia on Veterinary Epidemiology and Economics, Vina del Mar, Chile, p. 334.

Oparinde, A., Birol, E., 2011. Farm Households' Preference for Cash-Based Compensation Versus Livelihood-Enhancing Programs, Available: https://core. ac.uk/download/files/153/6314942.pdf (Accessed: December 14, 2015). 
Orme, B., 2009. Sample size issues for conjoint analysis studies. Sawtooth Software Research Paper Series. Sawtooth Software; 2009.

Otienno, D.J., Ruto, E., Hubbard, L., 2011. Cattle farmers' preferences for disease free zones in Kenya: an application of the choice experiment method. J. Agric. Econ. 62, 207-224

Palmer, S.E., Sully, Sarah, Max, M., Farida, Fozdar, 2009. Farmers, animal disease reporting and the effect of trust: a study of west australian sheep and cattle farmers. Rural Soc. 19.

Palmer, S., 2009. Factors Affecting Livestock Disease Reporting and Biosecurity Practices: A Study in West Australian Sheep and Cattle Producers. Murdoch University, Australia.

R core team, 2013. R: A Language and Environment for Statistical Computing. R Foundation for Statistical Computing, Vienna, Austria., pp. 2013 (Available: http://www.R-project.org/).

Rao, K.D., Ryan, M., Shroff, Z., Vujicic, M., Ramani, S., Berman, P., 2013. Rural clinician scarcity and job preferences of doctors and nurses in India: a discrete choice experiment. PLoS One 8, e82984, http://dx.doi.org/10.1371/journal. pone.0082984.

Roessler, R., Drucker, A.G., Scarpa, R., Markemann, A., Lemke, U., Thuy, L.T., Valle Zárate, A., 2008. Using choice experiments to assess smallholder farmersá preferences for pig breeding traits in different production systems in North-West Vietnam. Ecol. Econ. 66, 184-192, http://dx.doi.org/10.1016/j. ecolecon.2007.08.023, Special Section: Integrated Hydro-Economic Modelling for Effective and Sustainable Water Management.

Sadique, M.Z., Devlin, N., Edmunds, W.J., Parkin, D., 2013. The effect of perceived risks on the demand for vaccination: results from a discrete choice experiment. PLoS One 8, e54149, http://dx.doi.org/10.1371/journal.pone.0054149.
Thong, N.T., Hung, N.M., 2014. Positioning Vietnam's Pangasius Catfish in the French market using discrete choice model. J. Sci. Technol. Dev. 17.

USDA, 2015. Foot-and-Mouth Disease (FMD) Reponse: Ready Reference Guide-quarantine, Movement Control, and Continuity Business, Available at ttps://www.aphis.usda.gov/animal_health/emergency_management/ downloads/fmd_rrg_cob_qmc_plan.pdf (Accessed date: 11/6/2016).

WHO, 2012. How to conduct a Discrete Choice Experiment for health workforce recruitment and retention in remote and rural areas: User guide with case studies.

World Bank, 2006. Enhancing control of Highly Pathogenic Avian Influenza in Developing Countries through compensation: Issues and good practice.

$\mathrm{Xu}, \mathrm{P}$., Wang, Z., 2014. Country of origin and willingness to pay for pistachios: a Chinese case. Agric. Food Econ. 2, 1-16.

Yakhshilikov, Y., Birol, E., Tiongco, M., Narrod, C., Friedman, J., 2009. A contigent valuation study on Indonesian farmers' willingness to accept compensation for poultry. ILRI/IFPRI - HPAI Research Brief No. 18, 6 pp.

Zander, K.K., Garnett, S.T., 2011. The economic value of environmental services on indigenous-held lands in Australia. PLoS One 6, e23154.

Zhang, H., Kono, H., Kubota, S., 2014. An integrated epidemiological and economic analysis of vaccination against highly pathogenic porcine reproductive and respiratory syndrome (PRRS) in thua thien hue province. Vietnam. Asian-Australas. J. Anim. Sci. 27, 1499-1512, http://dx.doi.org/10.5713/ajas. 2014.14060. 